\title{
Curriculum Design for Building and Developing the Social-Emotional Skills of Preschoolers
}

Trifan Irina-Mihaela, Chiș Olga 


\title{
Curriculum Design for Building and Developing the Social-Emotional Skills of Preschoolers
}

\author{
Trifan Irina-Mihaela ${ }^{a *}$, Chiș Olga ${ }^{b}$ \\ ${ }^{a}$ The Faculty of Sciences and Letters "Petru Maior", George Emil Palade University of Medicine, Pharmacy, Science and Technology of Tîrgu \\ Mureş, Str. Nicolae Iorga, Nr. 1, Târgu Mureș, 540088, Romania \\ ${ }^{b}$ The Faculty of Psychology and Educational Sciences, Babeș-Bolyai University, 7 Sindicatelor Street, Cluj-Napoca, 400029, Romania \\ *Corresponding author: irina.trifan@umfst.ro
}

\section{Abstract}

\section{Keywords:}

social - emotional skills; understanding emotions; emotional regulation
The present study investigates the theoretical, methodical and practical aspects which emphasize the importance of the formation and development of social and emotional skills during early years, which have a major impact over children's long-term growth, while also assuring their adjustment in society, the cut down of unwanted behaviours and provides social and emotional well-being for the preschooler.

The steps dedicated for the pedagogical experiment have had the purpose of verifying the efficacy of the application of the project - The Development of Social and Emotional Skills Curriculum (DeCo - SE)- and was targeted towards building and growing said skills for the last year preschoolers. The results of the research revealed that the efficiency of applying a curriculum based on building and developing the social and emotional skills of preschoolers. We conclude that the study gave promising results on the prevention and reduction of undesirable behaviors, the identification of emotions, tolerance to frustration, relaxation through deep breathing techniques, methods of controlling anger and destructive behaviors among preschoolers. The comparative results presented in this study reinforce the findings of other international studies (Merrell et al., 2008), according to which the implementation of The Development of Social and Emotional Skills Curriculum (DeCo - SE) contributes to reducing undesirable behaviors, children being modeled in a positive way, having a positive social attitude, managing to easily adjust their emotions.

\section{Zusammenfasung}

\section{Schlüsselworte:}

sozial - emotionale Kompetenzen; Emotionen verstehen; emotionale Regulierung
Die vorliegende Studie untersucht die theoretischen, methodischen und praktischen Aspekte, die die Bedeutung der Bildung und Entwicklung sozialer und emotionaler Kompetenzen in den ersten Jahren hervorheben. Diese Kompetenzen haben einen großen Einfluss auf das langfristige Wachstum der Kinder und gewährleisten gleichzeitig ihre Anpassung an die Gesellschaft, reduzieren unerwünschter Verhaltensweisen und und sorgen für soziales und emotionales Wohlbefinden des Vorschulkindes.

Die für das pädagogische Experiment vorgesehenen Schritte hatten den Zweck, die Wirksamkeit der Anwendung des Projekts "Lehrplan für die Entwicklung sozialer und emotionaler Fähigkeiten" (DeCo-SE) zu überprüfen, und zielten darauf ab, diese Kompetenzen für Vorschulkinder im letzten Jahr des Kindergartens aufzubauen und auszubauen. Die Ergebnisse der Forschung zeigten die Effizienz der Anwendung eines Lehrplans, der sich auf dem Aufbau und der Entwicklung der sozialen und emotionalen Fähigkeiten von Vorschulkindern basiert. Wir fassen zusammen, dass die Studie vielversprechende Ergebnisse zur Prävention und Reduzierung unerwünschter Verhaltensweisen, zur Identifizierung von Emotionen, zur Toleranz gegenüber Frustration, zur Entspannung durch Tiefatmungstechniken, zu Methoden zur Kontrolle von Wut und zu destruktivem Verhalten bei Vorschulkindern lieferte. Die in dieser Studie vorgestellten Vergleichsergebnisse bestätigen die Ergebnisse anderer internationaler Studien (Merrell et al., 2008), wonach die Implementierung des Lehrplans für die Entwicklung sozialer und emotionaler Fähigkeiten (DeCo - SE) zur Reduzierung unerwünschter Ereignisse beiträgt; also Kinder werden positiv modelliert, haben eine positive soziale Einstellung und können ihre Emotionen leicht anpassen.

\section{Introduction}

Understanding and managing social emotions interacting and relating with same-age children, building positive relationships, being assertive and responsible - can be learned and developed at any age, but the advantages are bigger if the development strategies are applied at an earlier age. Children are using their acquired social and emotional skills during everyday activities, especially when they have to socialize with other people (Ilovan et al., 2016; Scridon \& Ilovan, 2015, 2016). Kids that benefit from well-built social and emotional skills will be able to form and keep 
friendships, while also having a positive attitude about learning and social events (Dulamă et al., 2015; Ilovan et al., 2018). These types of children are accepted in their group of friends and they adapt easily because they are more confident and have a bigger chance of academic success than others. On a long term, these kids will be able to develop and maintain long-lasting friendships, they will be efficient parents, will be able to find and keep a job, to work with others and be mentally and physically healthy.

The development of the new educational project implies new approaches and concepts that are meant to facilitate the evolution of contemporary didactics (Dulamă \& Ilovan, 2015; Dulamă, Ilovan \& Magdaş, 2017; Dulamă et al., 2019), so that these tactics will enforce a major evolution for the actual educational strategy. Therefore, we are talking about the interest we show in the process of social and emotional skills growth. The theme of the project is subsumed under actual methods of holistic approach in regards to scientific knowledge and it proposes to present well-documented pedagogical solutions for the optimization of the national curriculum. The importance of this project is magnified by the necessity of reorganizing the actual curriculum through formulating final ideas that would help the development of the social and emotional skills, in accordance with the European skills.

\section{Theoretical foundation}

A feature of early intervention is the cultivation of the child's social and emotional skills. They can support and guide the child in certain moments of his/hers life when he or she could be full of negative emotions, so that, in the end, they have positive social relationships (Denham \& Weissberg, 2004). According to researchers Doll, B. \& Lyon, M.A. (1998) and Matsen (2001), preschoolers, regardless of their background, can be taught how to adapt and mobilize for school success and to combat potential difficulties that may arise.

Early intervention programs that target the child's social and emotional development largely eliminate the risks and adversities that preschoolers and their families may face throughout their lives (Matsen, 2001). Daniel Goleman (1995), in his paper, anticipated that programs that focus on enhancing emotional intelligence during preschool years, will help prevent any problems that may occur in children. Understanding our own emotions and other people's emotions, the capacity to control those emotions and behaviours, but also the collaboration between peers and teachers offers the security the child needs. Children need to be able to cooperate, to follow instructions and be attentive. Based on what we've already mentioned, we could say that the development of curriculum projects is essential for the future academic success of a certain child.
The reconfiguration of the actual curriculum, with an emphasis on the introduction of social and emotional skills in order to actualize it, represents an important step in this study. The draft curriculum we propose aims to improve, explain and to use in the educational activities in kindergarten the most appropriate techniques and strategies for training social and emotional skills, in a way that leads to the development of theory and practice social and emotional education in kindergarten. This research has been conducted due to the necessity of finding practical solutions to the flaws of the actual curriculum. The fundamental aspects of our proposed curriculum are centered on the development of the social and emotional skills. Salovey \& Sluyter (1997) offer a revised version of the definition of emotional intelligence, stating that this implies the ability to identify, understand and express emotion in a clear way; the ability to use or generate feelings, to understand and to control them, with the aim of promoting development both emotionally and intellectually.

\section{Research methodology}

The research had the purpose to verify the efficacy of the curriculum project named The Development of Social and Emotional Skills Curriculum (DeCo - SE), based on the growth of indicated skills during the last year of kindergarten. The goal of the research is to test the efficacy of the curriculum project. Therefore, we decided to conduct a comparative analysis on the results we got from applying this curriculum, alongside the curriculum for children aged 3 to 6-7 years.

Enforcing the Development of Social and Emotional Skills Curriculum (DeCo - SE), which emphasizes educational strategies and techniques that help eradicate unwanted behaviours, while it also solves interpersonal problems, communication, interaction and relationship problems, it manages to significantly influence the growth of social and emotional skills of preschoolers in their last year at kindergarten. It is assumed that there are notable differences between the scores obtained from the experimental sample and the control sample, during the teacher-preschooler relationship scale (STRS), after the curriculum was implemented. The teacher-preschooler relationship scale (STRS) is designed to be used in the assessment of children aged 3 to 8 years. A well-known tool in the United States, for assessing the preschool-educator relationship, is the This is a self-assessment tool consisting of 28 items developed according to the model of attachment theory (Waters \& Deane, 1985) and based on a research of the literature on the study of teacher-child interaction. 


\section{Table 1. Research variables}

The independent
variable of the
research $\quad \begin{gathered}\text { The dependent variables of the } \\ \text { research }\end{gathered}$

Implementing a

part of the

Development of

Social and

Emotional Skills

Curriculum to last

year preschoolers

\section{The degree of emotional development is quantified by:}

\section{The degree of social development is quantified by:}

$\begin{array}{ll}\text { understanding } & \\ \text { and expressing } & \text { social } \\ \text { personal } & \text { relationships } \\ \text { emotions } & \text { pro-social } \\ \text { understanding } & \text { behaviour } \\ \text { emotions } & \text { rule } \\ \text { regulating } & \text { compliance } \\ \text { emotions } & \end{array}$

During our research, we proposed a sample of 146 preschoolers. The preschoolers were selected on the account of their age, kindergartens, teachers, class, gender. The research was conducted in 3 kindergartens from TîrguMureș.

While selecting the content sample, we've taken into consideration the fact that the experiment was going to take place during a whole day (during personal development, games and didactic activities). The content sample complied with the 3 to 6-7 years old rule. The method used during the experiment followed the curriculum entirely. The only interventions that took place were in the implementation of specific development and growth of social and emotional skills. The goal of this phase was to identify the initial level of social and emotional behaviors to 6-7 years preschoolers, both in the experimental and the control samples.

The teachers who were involved in the research participated first in a formative course called "Techniques and strategies used for the formation and development of social and emotional skills for preschoolers". During the course, which took place at Casa Corpului Didactic Mureș, the teachers were taught different strategies to help with the development of social and emotional skills (identifying emotions, frustration tolerance), fixing unwanted behaviors and fixing problems between peers. The strategies were taught exclusively through direct instruction and roleplay.

The teachers were given the curriculum project in order to get familiarized with its contents before being officially implemented. In January 2017, the curriculum project was implemented to the experimental sample. It contained 10 themes that approached the emotional well-being of preschoolers. The measuring data contained The teacher- preschooler relationship scale (STRS; Pianta, 2001).

In order to validate the curriculum project, it is necessary to utilize two types of groups or samples, an experimental one and a control one. For the experimental group, we will implement the formative program and emphasize the differences between the two steps of the evaluation, while also investigating the control sample.

The data processing was done in different steps, while taking into account certain necessities in regards to verifying scientific criteria translated from Anglo-Saxon literature: faithfulness analysis, factorial confirmation analysis, power analysis, descriptive analysis and comparative analysis.

In order to obtain the correct validation of the intervention program, a few comparison steps had to be followed. The first type of comparison (in-between subjects) uses the " $\mathrm{t}$ " parameter for independent samples in order to measure the value of means obtained by the experimental sample and by the control sample. Just like we mentioned in the hypothesis, we are expecting the means to be similar before the implementation of the curriculum, because the children have been selected aleatorily.

The project Development of Social and Emotional Skills Curriculum (DeCo-SE), that we are proposing wants to promote the most adequate techniques and formation strategies for social and emotional skills. Children who experiment stimulating learning techniques socially and emotionally are capable to identify their own emotions and of other people, and to use their cognitive abilities to solve conflictual situations.

The strategies and techniques of social and emotional education, intervention, represent methods through which the teacher can learn the children the necessary abilities in order for them to develop harmoniously. The practice we discuss is an important resource that will help the kindergarten teacher with the implementation of the project. Other studies show that the first five years of life are extremely important in the development of social and emotional abilities. The relationships they have with their own peers and with the adults are of utmost importance for the development of their own identities and feeling of belonging. Therefore, the teacher plays a significant role by promoting the social and emotional abilities, both during childhood and afterwards.

The formative experimental phase focused on creating and implementing the curriculum project in the experimental sample. The principles of the intervention plan were: the preschoolers were to be guided by teachers authentically and quality-based; the teachers were to facilitate the process of learning holistically by planning, projecting and implementing relevant learning experiences; preschoolers should be engaged actively through games in 
order to develop their own social and emotional skills.

Based on the curriculum project, the teachers carefully planned the acquisitions of these abilities during daily activities and games with their children. Knowing and understanding the way children develop and learn can help the teachers to plan and facilitate important learning experience for the children. The activities were thought and implemented in such a way that the children were able to form their own self-consciousness, strong suits and skills.

During this project, each type of activity aimed to regulate emotions and teach children how to have positive interactions with their peers, while also emphasizing learning strategies for social and emotional skills.

Table 2. Social and emotional skills promoted in project Development of Social and Emotional Skills Curriculum (DeCo - SE)

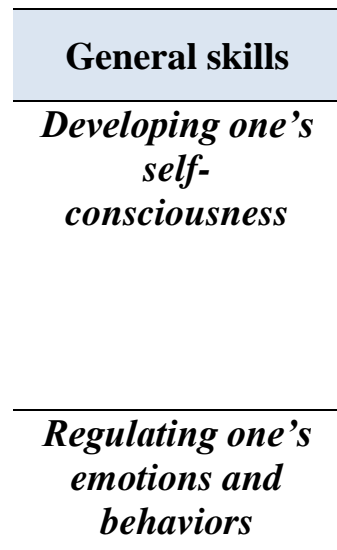

Manifesting pro-
social, diversity
accepting
behaviors
Communications, interaction and relating with others

Assuming responsibility for one's actions

\section{Results}

In order to obtain the correct validation of the intervention program, a few comparison steps had to be followed. The first type of comparison (in-between subjects) uses the " $t$ " parameter for independent samples in order to measure the value of means obtained by the experimental sample and by the control sample. Just like we mentioned in the hypothesis, we are expecting the means to be similar before the implementation of the curriculum, because the children have been selected randomly.

After the implementation of the curriculum, in the final phase, regarding the experimental sample, we are expecting higher levels of social and emotional skills, and lower behavioral problems. The insignificant differences in between the experimental and control samples are considered essential and mandatory for the final results, mainly because the different levels found during the final phase might not be related to the initial phase and therefore not to the implemented curriculum. The second type of comparison uses the same "t" parameter, but this time it refers to the pair samples or associated ones, and it compares preschoolers from the same samples before and after the implementation of the curriculum. We are expecting a higher level of social and emotional skills for the experimental sample and a decrease in problematic behavior. As for the control sample, in which case there wasn't implemented any formative program, only the usual curriculum, we are expecting slight changes, but not of big importance. The absence of differences in the control sample is important, because if there were any bigger differences, even without implementing the curriculum, the project would be useless.

Analyzing the values of the comparison indices, both for the independent samples and for the pair samples, for the two samples, it can be said that the implemented program for increasing social skills is efficient. Even though the initial level of social competencies is located in the area of high functionality, yet its level increases under the influence of the formative program, the children described by high social skills and the tendency to be extremely pleasing to colleagues and adults is even more evolving. In the case of the control group, without the influence of the training program, the situation remains unchanged, the differences between the final and the initial phase being insignificant in this case. In this situation we can discuss the confirmation of the specific hypothesis formulated and the rejection of the hazard or chance hypothesis, the results obtained due to the implemented training program. Thus, the inferential approach demonstrates the effectiveness of the formative program. 
Table 3 Pair samples scores (baseline - final) and materiality thresholds for the experimental group in the case of Student Teacher Relationship Scale (STRS)

\begin{tabular}{|c|c|c|}
\hline $\begin{array}{l}\text { Student Teacher } \\
\text { Relationship Scale } \\
\text { (STRS) }\end{array}$ & $\begin{array}{l}\text { Initial } \\
\text { results } \\
\text { Percent }\end{array}$ & $\begin{array}{c}\text { Final } \\
\text { results } \\
\text { Percent }\end{array}$ \\
\hline Conflict & 19,65 & 16,66 \\
\hline Closeness & 32,94 & 41,66 \\
\hline Dependency & 9,984 & 8,516 \\
\hline Total score & 62,56 & 66,84 \\
\hline \multicolumn{3}{|c|}{$\begin{array}{l}\text { Table } 4 \text { Pair samples scores (baseline - final) and } \\
\text { materiality thresholds for the control group in the case of } \\
\text { Student Teacher Relationship Scale (STRS) }\end{array}$} \\
\hline $\begin{array}{l}\text { Student Teacher } \\
\text { Relationship Scale }\end{array}$ & $\begin{array}{l}\text { Initial } \\
\text { results }\end{array}$ & $\begin{array}{c}\text { Final } \\
\text { results }\end{array}$ \\
\hline (STRS) & Percent & Percent \\
\hline Conflict & 21,46 & 21,71 \\
\hline Closeness & 31,93 & 32,13 \\
\hline Dependency & 10,70 & 10,89 \\
\hline Total score & 64,10 & 64,74 \\
\hline
\end{tabular}

The comparison of paired samples for the experimental group is significant for all types of child-educator interaction: Conflict $(\mathrm{t}=4,575 ; \mathrm{p}<0,01)$, Closeness $(\mathrm{t}=$ $6,932 ; \mathrm{p}<0,01)=5.959 ; \mathrm{p} \& \mathrm{lt} ; 0.01)$. In the case of the control group, no significant values of the comparison indices for any component of the evaluated pedagogical relationship are identified. The values of the comparison indices and the significance thresholds in this case are: Conflict $(\mathrm{t}=1,435 ; \mathrm{p}>0,05)$, Closeness $(\mathrm{t}=1,430 ; \mathrm{p}>0,05)$ 05).

It is also confirmed in this case the effectiveness of the implemented program, the relationship between children and educators being considered less negative or conflictual, educators perceiving children as less furious and unpredictable and consequently feeling safer, confident in professional skills and more less exhausted by the sustained effort to manage conflict situations.

At the "Closeness" scale the values increase after the formative program implementation, the relationship between children and educators being closer and warmer, communication being more efficient and more supportive behavior. On the "Dependency" scale, the significant drop in the level represents important steps that children do in their effective way of educating them. It increases selfconfidence, the ability to make optimal decisions, and relieves the educator of the exaggerated attention he has to give. We also discuss in this situation the confirmation of the specific hypothesis and the rejection of the hazard or chance hypothesis.

The whole methodological approach is preserved in the case of the assessment of emotional competences by educators, the average values in the bar graphs, comparisons and the relevant significance thresholds being verified in this way.

We consider the overall hypothesis of our work to be the application of Development of Social and Emotional Skills Curriculum (DeCo-SE) that valorizes strategies and techniques of socio-emotional education (identification of sentiments, tolerance to frustration), intervention strategies in modeling undesirable behaviors and strategies to solve interpersonal problems (relaxation through deep breathing techniques, methods of anger control and destructive behaviors) significantly influence the formation of social and emotional skills of large group preschoolers.

\section{Discussions}

The strategies for training the social and emotional behaviors, proposed through the training program named Development of Social and Emotional Skills Curriculum (DeCo-SE), were based on: knowing the child's strengths, his / her preferences in terms of activities and play; positive and respectful interactions with the child's feelings, the ability to calm the child quickly, respect for cultural differences, the ability to listen to the child's ideas, encouragement to express feelings, providing explanations when the child's program undergoes some changes, shaping a certain behavior, encouraging the child's independence and accountability.

The research undertook the effects of the curriculum project implementation, and the obtained results revealed that the behavioral problems of preschoolers diminished significantly, while those in the control group did not undergo any changes.

\section{Conclusions}

The comparative results presented come to reinforce the findings of other international studies (Merrell, 2010, Merrell et al., 2008), according to which the implementation of Development of Social and Emotional Skills Curriculum (DeCo-SE) contributes to reducing undesirable behaviors, children being modeled in a positive way, having a positive social attitude, managing to easily adjust their emotions. These results underscore once again that the program is pragmatic and confirms the hypothesis formulated by us.

Relations between educators and preschoolers have improved overall in all aspects, proving the effectiveness of the curriculum project which was implemented. In addition, the level of conflicts dropped significantly in the groups where the curriculum project was applied, while in the control groups the level of conflict increased. It can be said 
that by participating in the activities included in the curriculum project, preschoolers from the experimental group have been given the opportunity to exercise control of their own emotions in an environment where they feel comfortable, which has led to a significant increase in the levels of social skills and emotional and a reduction in behavioral problems.

Authors note: The authors have equal contributions to this article.

Trifan Irina-Mihaela is a Ph.D. University Lecturer at the Teacher Training Department, George Emil Palade University of Medicine, Pharmacy, Science and Technology of Tîrgu Mureş Romania. Her professional and research interests include: practices in early childhood education, creative curriculum with reference to young children's social and emotional development.

Chiş Olga is a senior lecturer at the Department of Educational Sciences, Babeș-Bolyai University, ClujNapoca, Romania. She graduated Ph.D. in educational sciences and her fields of interest include: parental education, children's literacy, assessment of children in kindergarten and primary school.

\section{References}

Denham, S. A., Weissberg, R. P. (2004). Social-emotional learning in early childhood: what we know and where to go from here. In E. Chesebrough, P. King, T.P. Gullota, \& M. Bloom (Eds.), A blueprint for the promotion of prosocial behavior in early childhood (pp. 13-51). Kluwer Academic/Plenum Publishers, New York.

Dulamă, M.E. \& Ilovan, O.-R. (2015). Development of the Geography school curriculum in Romania, from the 18th century to 1989.Transylvanian Review, 24 (Supplement 1), 255-284.

Dulamă, M.E., Ilovan, O.-R. \& Magdaş, I. (2017). The forests of Romania in scientific literature and in Geography. Teachers' perceptions and actions.Environmental Engineering and Management Journal, 16(1), 169-186.

Dulamă, M.E., Ilovan, O.-R., Bagoly-Simó, P. \& Magdaș, I. (2019). Development of the geographical education system in Romania, under the impact of World War II and during the transition to communism.Transylvanian Review, 24 (Supplement 2) - under print.

Dulamă, M.E., Ilovan, O.-R., Ciascai, L. \& Maroşi, Z. (2015). E-learning Geography. How powerful is Facebook for Geography university students? Proceeding of the 10th International Conference on Virtual Learning, pp. 121-127.

Goleman, D. (1995) Emotional intelligence: Why it can matter more than $I Q$, New York: Bantam Books, New York.

Ilovan, O.-R., Dulamă, M.E., Boţan, C.N., Havadi-Nagy, K.X., Horvath, Cs., Niţoaia, A., Nicula, S. \& Rus, G.M. (2018). Environmental education and education for sustainable development in Romania. Teachers' perceptions and recommendations. Journal of Environmental Protection and Ecology, 19(1), 350-356.

Ilovan, O.-R., Jordan, P., Havadi-Nagy, K.X. \& Zametter, T. (2016). Identity matters for development: Austrian and Romanian experiences. Transylvanian Review, 25 (Supplement 1), 261-276.

Masten, A.S. (2001). Ordinary magic: Resilience processes in developmen, American Psychologist

Merrell, K. W., Juskelis, M. P., Tran, O. K., \& Buchanan, R. (2008). Social and emotional learning in the classroom: Evaluation of Strong Kids and Strong Teens on students' social-emotional knowledge and symptoms. Journal of Applied School Psychology.

Pianta, R. C. (2001). Student-teacher relationship scale: Professional manual. Lutz, FL: Psychological Assessment Resource.

Salovey, P., Sluyter, D.J. (ed.), (1997). Emotional Development and Emotional Intelligence: Educational Implications. BasicBooks, New York.

Scridon, I. \& Ilovan, O.-R. (2015). The Zipsers' ethnic identity in Vișeu de Sus/Oberwischau, Romania, in the context of inter-ethnic relationships. Mitteilungen der Osterreichischen Geographischen Gesellschaft, 157, 151-168.

Scridon, I. \& Ilovan, O.-R. (2016). Approaching the Other in the Zipser community. Identity issues and methodological insights into geographical cross-cultural research.Transylvanian Review, 25(1), 55-73.

Waters, E. \& Deane, K. (1985), Defining and assessing individual differences in attachment relationships: $Q$ methodology and the organization of behavior in infancy and early childhood, In I. Bretherton \& E. Waters (Eds.), Monographs of the Society for Research in Child Development. USA: University Of Chicago Press. 